\title{
THE MEANING-BASED APPROACH TO ASSESSING THE IMAGES OF YOUNG AND ELDERLY WOMEN AND MEN
}

\author{
Shulamith Kreitler \\ School of Psychological Sciences, Tel-Aviv University (Israel)
}

\begin{abstract}
The study was inspired by the widely documented evidence about socio-cultural changes in the status and behavior of women in recent decades. The objective was to compare the images that younger and older women have of younger and older women and to compare these images with the images they have of younger and older men. It was expected that the differences would be larger in regard to the images of women than of men. The participants were 80 younger (25-40 years old) and 80 older women (50-65 years old). The method consisted in administering a meaning-based questionnaire of 43 items which provided scores for four clusters referring to perceptual-sensory, actional-dynamic, experiential-cognitive and contextual-situational aspects. The assessed images were of young women, older women, young man and older men. Mean comparisons between and within groups showed highly significant differences in the images of women and men, in most clusters, more in regard to women than to men. The findings indicate major differences in conceptions relating to gender and age. The meaning-based assessment tool proved to be sufficiently sensitive to differences and sufficiently comprehensive to provide an overall perspective.
\end{abstract}

Keywords: Gender, age, meaning, conception, women.

\section{Introduction}

In recent years big changes have taken place in the status and functioning of women, mainly in Western society. These changes have come about through the fight of women, legal regulations concerning equality of rights, changes in social structures and life style and the increased participation of women in education, economy and politics. In most Western societies' women have come a long way towards equality in employment, education, management and politics (Eagly, Diekman, Johannessen-Schmidt, \& Koenig, 2004; McLean \& Ramsey, 2002). The internet and media have also played their role in regard to women's freedom (Butkowski, Dixon \& Week, 2019). As a result, women have become more active in different public positions, express more openly their views, expect to be treated in a more egalitarian manner and fight more openly for their rights and the manner in which they are treated (Cotter, Hermsen, \& Vanneman, 2011). Parallel changes have come about in fashion styles, involvement in sport and sexual freedom. It was expected that these socio-cultural changes would be reflected in the conceptions of women about 'being a woman'.

\section{Objectives}

The study focused on comparing the conception of women of two age groups about a young and an elderly woman. The two age groups were young women, growing up in the already changed world of the last two decades, and older women of former generations. The hypotheses were that there would be significant differences in the conceptions of younger women and those of older women, particularly in regard to the image of a young woman. Further, it was expected that younger women would evidence larger differences than older women in their conceptions of young and old women. More specifically, major differences in the images of younger and older women were expected in regard to the activities of women and their physical appearance. The rationale was that these domains represent those on which the majority of the feminist and equal right movements focused (Thoma, Hediger, Sundaram et al., 2012). For control purposes also the images of younger and older men were studied. It was expected that younger and older women would have more similar conceptions of younger and older men and would have fewer differences between the images of younger and older men. The rationale was that the socio-cultural differences in the last few generations seem to have affected the life of men to a lesser degree than the life of women. 


\section{Method}

\subsection{Design}

The basic design of the study consisted in between-group and within-group comparisons. The groups were younger and older women, while the compared constructs were young woman and elderly woman, young man and older man.

\subsection{Participants}

The participants were 160 women including 80 younger women ( 25 to 40 years old) and 80 older women (50 to 65 years old). In each sample over $70 \%$ were married and engaged in some kind of occupation. The women were recruited from offices in a university and a hospital as well as from internet groups.

\subsection{Tools}

The major tool of the study was the meaning-based questionnaire of concepts, which is grounded theoretically in the cognitive theory of meaning (Kreitler, 2014; Kreitler \& Kreitler, 1990). Accordingly, it includes items that refer to the basic content categories of meaning (called meaning dimensions) which are used by individuals to express or communicate meanings of any kind of stimuli. The meaning categories have been identified on the basis of a rich body of data that included meaning responses of several thousands of subjects in different countries and cultures, differing in age, education, profession and gender, who were asked to communicate the meaning of a variety of referents differing in abstraction, and content spheres (e.g. human, animal, plant, nature, or artificial/synthetic). Examples of the meaning categories are the action of the referent, its sensory features, time and space qualities, emotional aspects, development and possessions. Meaning categories of this kind represent basic cognitive processes applied in any kind of cognitive operation (e.g., problem solving, decision making, cognitive aspects of personality tendencies or traits) as well as communications of meanings of all kinds (Kreitler, 2013; Kreitler, 2014). The 22 meaning dimensions were used for generating items that would represent various aspects of the studied images. Similarly constructed questionnaires were used in other domains (e.g., Kreitler, 2018). After being administered to pretest samples that enabled removing unclear items or those producing responses with no variability, the questionnaire included 43 items. The subjects were requested to check in regard to each item how characteristic it was for the studied construct. There were four response options ranging from "Highly characteristic" to "not at all characteristic", scored as 4 to 1 , respectively. The Cronbach alpha reliability was .76. For purposes of data elaboration the items were grouped into the four following clusters, on the basis of their content, as in other similarly constructed questionnaires: items focused on sensory-perceptual aspects (10 items), actional-dynamic aspects (12 items), experiential-cognitive aspects (11 items), and contextual-situational aspects (10 items). [see Appendix for the questionnaire and scoring). Four questionnaires were prepared with the same format referring to the image of a young woman (see Appendix), to the image of an elderly woman, to the image of a young man and to the image of an elderly man.

\subsection{Procedure.}

Every subject got the four questionnaires, in random order. The questionnaires were administered unanimously in a sequence. The following demographic information was requested: year of birth, marital status, years of education, and occupation.

\section{Results}

Table 1 presents the results concerning the four examined images, i.e., of younger woman, elderly woman, young man, older man. The findings consist of means and mean comparisons of the responses in the four clusters of items, i.e. perceptual-sensory, actional dynamic, experiential-cognitive and contextual-situational. Considering each image separately shows that for young women, the highest clusters in regard to young woman are perceptual-sensory and contextual aspects, for older women and young man actional-dynamic and experiential-cognitive aspects, and for older man actional-dynamic and contextual-situational aspects. For older women, the highest scores in regard to young woman are perceptual-sensory and contextual aspects, for older women actional-dynamic and contextual aspects, for young man experiential-cognitive and contextual aspects, and for older man perceptual-sensory and contextual aspects. This summary indicates a lot of variability across groups and constructs of images.

The same conclusion is supported by the results of mean comparisons in terms of t-tests. The within-group comparisons indicate that in the sample of young women, the images of young and elderly women differ significantly in three clusters except the actional-dynamic. The same holds for the images of young man and old man, because the difference in the actional-dynamic cluster is significant only on 
the $\mathrm{p}<.05$ level which does not reach the Bonferroni criterion. In the sample of older women, the images of young and elderly women differ significantly only in the perceptual-sensory and experiential-cognitive clusters, and the images of young man and old man differ significantly in the experiential-cognitive and contextual clusters, whereas the differences in the other clusters are either nonsignificant or do not pass the Bonferroni criterion.

Comparing the images of women and of men in the two samples shows that in all clusters the differences are significant.

Table 1. Comparing the responses of younger and older women in regard to the images of a young and an older woman and of young and older man.

\begin{tabular}{|c|c|c|}
\hline Young women & Older women & \\
\hline Image of young woman & Image of young woman & $\begin{array}{l}\text { t-test bet. } \\
\text { Groups }\end{array}$ \\
\hline $29.3 \quad[3.4]$ & $\begin{array}{lll}\text { a } & 25.4 & {[3.9]} \\
\end{array}$ & $6.742 * * *$ \\
\hline $\begin{array}{lll}\mathrm{b} & 25.6 & {[2.8]}\end{array}$ & $\begin{array}{lll}\mathrm{b} & 20.2 & {[2.0]} \\
\end{array}$ & $14.037 * * *$ \\
\hline $22.8 \quad[3.4]$ & $\begin{array}{lll}\text { c } & 21.3 & {[3.3]}\end{array}$ & $2.832 * *$ \\
\hline $28.5[4.1]$ & $\begin{array}{lll}\mathrm{d} & 26.8 & {[4.3]}\end{array}$ & $2.559 * *$ \\
\hline Image of elderly woman & Image of elderly woman & \\
\hline $\begin{array}{lll}\mathrm{a} & 21.6 & {[4.2]}\end{array}$ & $\begin{array}{lll}\mathrm{a} & 19.3 & {[4.2]} \\
\end{array}$ & $3.463 * *$ \\
\hline $24.9 \quad[4.5]$ & $\begin{array}{lll}b & 22.3 & {[4.5]} \\
\end{array}$ & $3.795 * *$ \\
\hline $28.5 \quad[4.5]$ & $\begin{array}{lll}\text { c } & 22.4 & {[4.0]}\end{array}$ & $9.062 * * *$ \\
\hline $\begin{array}{lll}\mathrm{d} & 19.6 & {[4.8]} \\
\end{array}$ & $\begin{array}{lll}\mathrm{d} & 27.2 & {[4.5]}\end{array}$ & $10.332 * * *$ \\
\hline $\begin{array}{l}\text { t-test within group } \\
\text { (young woman and } \\
\text { elderly woman) }\end{array}$ & $\begin{array}{c}\text { t-test within group } \\
\text { (young woman and elderly } \\
\text { woman) }\end{array}$ & \\
\hline a-a $14.798 * * *$ & $\begin{array}{ll}\text { a-a } & 10.815 * * *\end{array}$ & \\
\hline $\begin{array}{ll}\mathrm{b}-\mathrm{b} & 1.181 \mathrm{~ns} \\
\end{array}$ & b-b $1.998 *$ & \\
\hline $\begin{array}{ll}\mathrm{c}-\mathrm{c} & 9.039 * * * \\
\end{array}$ & c-c $3.149 * *$ & \\
\hline d-d $12.610^{* * * *}$ & $\begin{array}{ll}\mathrm{d}-\mathrm{d} & 0.575 \mathrm{~ns}\end{array}$ & \\
\hline Image of young man & Image of young man & \\
\hline $\begin{array}{lll}\mathrm{a} & 27.3 & {[4.5]}\end{array}$ & a $29.6 \quad[5.4]$ & $2.927 * *$ \\
\hline $\begin{array}{lll}b & 32.4 & {[5.1]} \\
\end{array}$ & $\begin{array}{lll}b & 31.4 & {[5.4]} \\
\end{array}$ & $1.204 \mathrm{~ns}$ \\
\hline $\begin{array}{lll}\text { c } & 30.7 & {[4.7]}\end{array}$ & c 32.2 [4.9] & $1.976^{*}$ \\
\hline $\begin{array}{llll}\mathrm{d} & 31.4 & {[4.0]} \\
\end{array}$ & $\begin{array}{lll}\mathrm{d} & 34.1 & {[3.5]} \\
\end{array}$ & $4.544 * *$ \\
\hline Image of older man & Image of older man & \\
\hline $\begin{array}{llll}\mathrm{a} & 29.5 & {[4.8]} \\
\end{array}$ & $\begin{array}{lll}\mathrm{a} & 31.4 & {[4.0]} \\
\end{array}$ & $2.720 * *$ \\
\hline b 30.8 [4.5] & b $29.5[4.9]$ & $1.748^{*}$ \\
\hline $\begin{array}{lll}\text { c } & 28.2[4.9] \\
\end{array}$ & c 27.8 [4.9] & $0.516 \mathrm{~ns}$ \\
\hline $\begin{array}{lll}\mathrm{d} & 33.6 & {[5.0]} \\
\end{array}$ & $\begin{array}{lll}\mathrm{d} & 31.3[4.7] \\
\end{array}$ & $2.998 * *$ \\
\hline $\begin{array}{c}\mathrm{t} \text {-test within group } \\
\text { (young man and older } \\
\text { man) }\end{array}$ & $\begin{array}{c}\mathrm{t} \text {-test within group } \\
\text { (young man and older } \\
\text { man) }\end{array}$ & \\
\hline $2.991 * *$ & $0.295 \mathrm{~ns}$ & \\
\hline $2.104 *$ & $2.331 *$ & \\
\hline $\begin{array}{ll}\mathrm{c}-\mathrm{c} & 3.293 * * \\
\end{array}$ & $5.679 * * *$ & \\
\hline d-d $3.073 * *$ & d-d $4.274 * * *$ & \\
\hline $\begin{array}{c}\mathrm{t} \text {-test within group } \\
\text { (young woman and young } \\
\text { man) }\end{array}$ & $\begin{array}{c}\text { t-test within group } \\
\text { (elderly woman and older } \\
\text { man) }\end{array}$ & \\
\hline $3.172 * *$ & $18.660 * * *$ & \\
\hline b-b $10.454 * * *$ & $11.024 * * *$ & \\
\hline $\begin{array}{ll}\mathrm{c}-\mathrm{c} & 9.870 * * * \\
\end{array}$ & $7.636 * * *$ & \\
\hline $\begin{array}{ll}\mathrm{d}-\mathrm{d} & 4.528^{* *}\end{array}$ & $7.636 * * *$ & \\
\hline
\end{tabular}

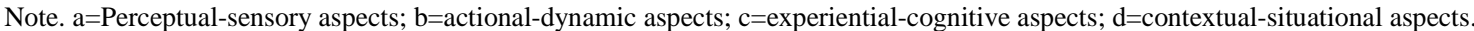
${ }^{a}$ In each column the first number is the mean, the second, in brackets is the standard deviation. 


\section{Discussion}

The results support the major hypothesis of the study that younger and older women would differ in the manner in which they conceptualize and present the images of young and elderly women. The two samples differed significantly in regard to all clusters concerning the images of young and elderly women. As expected, the differences in the conceptions of younger women tended to be larger than in older women (significant changes in three vs two clusters). Again, as expected, there are major differences in both groups in the perceptual-sensory items that refer to external appearance, but contrary to expectation not in regard to activity. However, the two samples differed also in their images of young and old men yet to a lesser degree than in regard to the images of women. The differences in regard to both male images were significant only in regard to the perceptual-sensory and contextual clusters. Hence there is some indication for support of the hypothesis in regard to the images of men.

\section{Conclusions}

The findings imply that both gender and age are important parameters that contribute to shaping the images of women and men. Younger women's conceptions differed somewhat more than those of older women. The fact that the differences in the images are so salient indicates that when dealing with them it is advisable to consider the images of women and men, old and young, as they are without generalizing. Another important conclusion is that the images of young and old women and men are reflected in all four clusters of features that encompass the physical appearance (perceptual-sensory cluster), action and behavior (actional-dynamic cluster), inner world (experiential-cognitive cluster) and external-situational characteristics (contextual -situational cluster). Hence, the meaning-based tool proved to be adequate for assessing the images of figures differing in gender and age in being both sensitive to differences as well as sufficiently comprehensive to reflect overall characteristics.

\section{References}

Butkowski, C. P., Dixon, T. L., \& Weeks, K. (2019). Body surveillance on instagram: Examining the role of selfie feedback investment in young adults women's body image concerns. Sex Role, Jan. 5, no pp.

Cotter, D., Hermsen, J. M., \& Vanneman, R. (2011). The end of the gender revolution? Gender role attitudes from 1977 to 2008. American Journal of Sociology, 117 (1), 259-289.

Eagly, A. H., Diekman, A. B., Johannesen-Schmidt, M.C., \& Koenig, A. M. (2004). Gender gaps in sociopolitical attitudes: A social psychological analysis. Journal of Personality and Social Psychology, 87(6), 796-816.

Kreitler, S. (2013). The construction of meaning. In D. Cervone, M. Fajkowska, M. W. Eysenck \& T. Maruszewski (Eds.). Personality Dynamics: Embodiment, Meaning Construction, and the Social World. Clinton Corners, NY: Eliot Werner Publications.

Kreitler, S. (2014). Meaning and its manifestations: The Meaning System. In S. Kreitler \& T. Urbanek (Eds.) Conceptions of meaning (pp. 3-32). Hauppauge, NY: Nova Publishers.

Kreitler, S. (2018). Meaningfulness of life and existential distress. Advances in Clinical and Experimental Psychology, 1(1), 1-10. DOI: 10.29011/ ACEP-101. 100001.

Kreitler, S., \& Kreitler, H. (1990). Cognitive foundations of personality traits. New York: Plenum.

McLean, S. A. \& Ramsey, J. (2002). Human rights, reproductive freedom, medicine and the law. Medical Law International, 5(4), 239-258.

Thoma, M. E., Hediger, M. L., Sundaram, R....Louis, G. M. B. (2012). Comparing apples and pears: Women's perceptions of their body size and shape. Journal of Women's Health, 21(10), 1074-1081. 
Appendix

\section{The Image of a Young Woman}

The following items describe the features that may characterize a normative young woman at present, in the current period. Please check in regard to each item to what extent you think it characterizes a young woman. Note: The four response alternatives are: Highly characteristic, Characteristic to a medium extent, Characteristics to a small extent, Not at all characteristic

1. Being active, doing things, performing things

2. Getting help, getting things from others, having others arrange things for her

3. Feeling that she belongs to something or someone

4. Developing, being in a state of development, feeling that she develops, that her life develops

5. Having a good ability to think, to understand, to analyze, to solve problems; having a good memory

6. Having a body with good proportions and dimensions

7. Dealing with things of which there are many, whose quantity is large

8. Caring about places in which she stays - country, location, home

9. Concerned about being esteemed, about whether others think well of her; whether others value her and her work

10. Being pressured by time; stressed by lack of time; being often late

11. Owning many things, having possessions, feeling that many things belong to her

12. Feeling that she has a task or purpose in life, that her work has a goal

13. Being aware of the causes for her behavior and for the things that she does

14. Being aware of the things that are affected by her, of the things and the people with whom she is in contact

15. Being concerned about having always the right kind of bodily weight

16. Having many emotional experiences, reacting emotionally to people and things, interested in learning new emotions, being able to feel deeply about things

17. Being concerned about having results to what she does or says; being aware of the results of her actions

18. Being in contact with people, having people around her most of the time

19. Being aware of belonging to a certain nation, to a certain community, to a certain group, gender, organization, team, feeling that she is part of a family

20. Having a variegated life, living a life of different kinds

21. Behaving in an aggressive manner; trying to control others and situations

22. Being aware of how things happen, of the manner in which life occurs

23. Being aware of different materials fulfilling a certain role in her life, e.g., water, air, metals and crystals, cotton and wool

24. Having a life with a certain structure, a life that is a continuum of events interrelated in some form; having an organized life

25. Having changes in her life

26. Wanting many things

27. Evoking in other people emotions like love or longing, sometimes even fear or anger, being loved

28. Having certain opinions and beliefs, believing in certain things

29. Being a source of inspiration for others, evoking in them thinking or understanding

30. Looking well, being physically beautiful, handsome

31. Being healthy, being in a good physical state

32. Being interested in learning to know many tastes, having food that tastes well, being able to taste things with an interesting taste

33. Having interesting and exciting physical sensations

34. Being able to listen a lot to music that she likes, enjoying music

35. Feeling pain in different body parts

36. Liking to be exposed in her environment to colors and forms that she likes

37. Concerned about being rich, having a lot of money

38. Leading a stable life, based on routine

39. Having a profession, a career; being achievement-oriented

40. Being concerned about having a skin and hair in good colors

41. Being in good control of her body

42. Contributing to others' welfare and well-being

43. Manipulative; managing things in ways that benefit her 